University of Nebraska - Lincoln

DigitalCommons@University of Nebraska - Lincoln

\title{
Rapid Assessment of Insect Fragments in Flour Milled from Wheat Infested with Known Densities of Immature and Adult Sitophilus oryzae (Coleoptera: Curculionidae)
}

\author{
Michael D. Toews \\ University of Georgia \\ Joel Perez-Mendoza \\ Schendel Pest Services \\ James E. Throne \\ USDA-ARS, Manhattan, KS, james.throne@ars.usda.gov \\ Floyd E. Dowell \\ USDA-ARS \\ Elizabeth Maghirang \\ USDA-ARS
}

See next page for additional authors

Follow this and additional works at: https://digitalcommons.unl.edu/usdaarsfacpub

Toews, Michael D.; Perez-Mendoza, Joel; Throne, James E.; Dowell, Floyd E.; Maghirang, Elizabeth; Arthur, Frank H.; and Campbell, James F., "Rapid Assessment of Insect Fragments in Flour Milled from Wheat Infested with Known Densities of Immature and Adult Sitophilus oryzae (Coleoptera: Curculionidae)" (2007). Publications from USDA-ARS / UNL Faculty. 2017.

https://digitalcommons.unl.edu/usdaarsfacpub/2017

This Article is brought to you for free and open access by the U.S. Department of Agriculture: Agricultural Research Service, Lincoln, Nebraska at DigitalCommons@University of Nebraska - Lincoln. It has been accepted for inclusion in Publications from USDA-ARS / UNL Faculty by an authorized administrator of DigitalCommons@University of Nebraska - Lincoln. 


\section{Authors}

Michael D. Toews, Joel Perez-Mendoza, James E. Throne, Floyd E. Dowell, Elizabeth Maghirang, Frank H. Arthur, and James F. Campbell 


\title{
Rapid Assessment of Insect Fragments in Flour Milled from Wheat Infested with Known Densities of Immature and Adult Sitophilus oryzae (Coleoptera: Curculionidae)
}

\author{
MICHAEL D. TOEWS, ${ }^{1}$ JOEL PEREZ-MENDOZA, ${ }^{2}$ JAMES E. THRONE, FLOYD E. DOWELL, \\ ELIZABETH MAGHIRANG, FRANK H. ARTHUR, AND JAMES F. CAMPBELL
}

USDA-ARS Grain Marketing and Production Research Center, 1515 College Avenue, Manhattan, KS 66502

J. Econ. Entomol. 100(5): 1714-1723 (2007)

\begin{abstract}
Milling wheat, Triticum aestivum L., infested with low densities of internal feeding insects can result in flour containing insect fragments. The Food and Drug Administration (FDA) enforces a standard or defect action level stating that a maximum of 75 insect fragments per $50 \mathrm{~g}$ of flour is allowed. However, the relationship between level of infestation and number of resulting fragments is not well documented, and a more rapid method for enumerating insect fragments is needed. We characterized the number of insect fragments produced from milling small lots of wheat spiked with known densities and life stages of Sitophilus oryzae (L.) (Coleoptera: Curculionidae). Insect fragments were enumerated with near-infrared spectroscopy (NIRS), a quick nondestructive procedure, and with the industry standard flotation method. Results showed that an individual small larva, large larva, pupa, or adult produced $0.4,0.7,1.5$, and 27.0 fragments, respectively. NIRS-predicted counts of $\leq 51$ (from small larvae), $\leq 53$ (from large larvae), $\leq 43$ (from pupae), or 0 (from adults) indicated that there were $<75$ actual fragments in that sample, because the upper bound of associated 95\% inverse prediction confidence intervals was less than the standard; NIRS-predicted counts of $\geq 98$, $\geq 117, \geq 108$, or $\geq 225$ fragments (same life stages as above) signaled that these flour samples contained $>75$ actual fragments. These data suggest that NIRS could be adopted for rapid assessment of insect fragments resulting from relatively low levels of infestation with immature life states, but that it was not accurate enough for enumerating insect fragments, relevant to FDA standards, resulting from adults.
\end{abstract}

KEY WORDS rice weevil, stored products, near-infrared spectroscopy (NIRS), internal insect infestation, insect fragments

Milling of wheat, Triticum aestivum L., infested with stored-product insects that develop and feed inside individual kernels, also known as internal infesting species, produces insect fragments in the finished product (Sachdeva 1978, Perez-Mendoza et al. 2005). Internal insect infestations in bulk wheat, unlike external insects, are not removed during the grain cleaning process before milling. Internal infestations can be detected before milling by holding wheat and waiting for adults to emerge from kernels (Storey et al. 1982), but this takes too long to be practical. Counts of insectdamaged kernels (IDK) are used to grade the level of infestation in wheat, but this method is unreliable because there is no correlation between insect-

Mention of trade names or commercial products in this publication is solely for providing specific information and does not imply recommendation or endorsement by the U.S. Department of Agriculture.

${ }^{1}$ Corresponding author: Department of Entomology, Coastal Plain Experiment Station, University of Georgia, 122 S. Entomology Dr., Tifton, GA 31793-0748 (e-mail: mtoews@uga.edu).

${ }^{2}$ Current address: Schendel Pest Services, 1826 S. Kansas Ave. Topeka, KS 66612 . damaged kernels and current insect infestation (Wingfield and Pedersen 1985, Russell 1988, PerezMendoza et al. 2004). More rapid detection methods include traditional techniques such as x-ray examination or crack and float (AACC 1995) and more advanced or experimental methods like near-infrared spectroscopy (NIRS), enzyme-linked immunosorbent assay (ELISA), or x-ray imaging (Quinn et al. 1992, Dowell et al. 1998, Karunakaran et al. 2003, Maghirang et al. 2003, Haff and Slaughter 2004, Toews et al. 2006). Most of these detection methods have not been commercially adopted due to practical constraints with speed, small sample size, detection accuracy, or equipment expense.

The exact relationships among differing insect species, life stages, and infestation densities, and the resulting fragments in milled products are largely unknown. Sachdeva (1978) estimated that Sitophilus granarius (L.) (Coleoptera: Curculionidae) adults produced 3 times more fragments than wheat infested with larvae. Perez-Mendoza et al. (2005) found that Rhyzopertha dominica (F.) (Coleoptera: Bostrichidae) 
adults and pupae produced 23 and $2.6 \times$ more fragments, respectively, than large larvae. Both of these studies showed that insect fragment counts increased proportionally with infested kernel densities. In the United States, the Food and Drug Administration regulates insect fragments in wheat flour with an average defect action level (DAL) of 75 fragments per $50 \mathrm{~g}$ flour (FDA 1997). Fragment counts are currently based on the standard flotation method (AOAC 1996). This method is labor-intensive, time-consuming, and expensive because each sample must be carefully heated and digested with hydrochloric acid before harvest of the floating insect fragments with suction filtration. The fragments must then be counted while viewed under a dissecting microscope.

Several studies previously described novel techniques to rapidly detect and quantify insect fragments. Kitto (1991) developed a sandwich ELISA for detection and quantification of myosin, an insect muscle protein. This technology is available in kits that can be used on whole grain or flour samples. Schatzki et al. (1993) determined that myosin content of individuals increased from 0.1 to $9.0 \mu \mathrm{g}$ from first through fourth instars, decreased to $1.9 \mu \mathrm{g}$ in pupae, and resolved at $6.6 \mu \mathrm{g}$ in adult S. granarius. Brader et al. (2002) demonstrated that the ELISA procedure was more accurate than $\mathrm{x}$-ray analyses, cracking, and flotation, or the standard flotation method for detecting S. granarius infestations under specific conditions. Perez-Mendoza et al. (2003) investigated using NIRS to predict insect fragments in flour, but their results showed limited success classifying fragments below the FDA defect action level. Recently, a more successful study demonstrated the utility of NIRS to enumerate $R$. dominica fragments resulting from milling grain spiked with large larvae, pupae, or adults (Perez-Mendoza et al. 2005). Perez-Mendoza et al. (2005) showed that a Bruker Optics Fourier-transform (FT) near-infrared (NIR) spectrometer (Bruker Optics, Billerica, MA) produced the most accurate fragment estimates in wheat flour among the four spectrometers tested.

Sitophilus oryzae (L.) (Coleoptera: Curculionidae) is a cosmopolitan internal infesting insect species (Rees 2004). The life cycle averages $35 \mathrm{~d}$ at $27^{\circ} \mathrm{C}$ and $69 \% \mathrm{RH}$, but larval development is generally complete in only $22 \mathrm{~d}$ at these conditions (Sharifi and Mills 1971). Oviposition rates of 344-384 eggs per female are possible under ideal conditions (Birch 1945). Females chew a hole and deposit individual eggs inside grain kernels where the individuals remain for the duration of the immature life stages. A gelatinous material is deposited behind the egg, effectively protecting the developing immature from exposure to insecticides applied directly to the grain. Freshly emerged adults remain inside the kernels for a few days before chewing out. In addition to insect fragments, internal infestations also may contaminate grain-derived foods with metabolic waste and caste skins. Bernton and Brown (1967) presented data showing that $\approx 10 \%$ of humans had positive allergic reactions to dermal applications of S. oryzae-dialyzed extracts.
Development of a rapid, accurate, and inexpensive method for quantifying insect fragments in finished flour is highly desirable to the milling industry. New methods that meet these simple criteria are likely to replace existing methods. Although the number of fragments is regulated, there is little information available on how many fragments are produced by milling wheat with a known number of infested kernels. Science-based thresholds that relate known infestations with number of insect fragments could greatly improve a miller's ability to produce acceptable flour. The objectives of this study were to 1) characterize the number of fragments in finished wheat flour resulting from milling known densities of wheat kernels containing small larvae, large larvae, pupae, or newly eclosed (preemergent) adults of S. oryzae; and 2) develop thresholds relative to each life stage and test the ability to predict fragment densities by using NIRS for rapid assessment of the number of insect fragments in a flour sample.

\section{Materials and Methods}

Insect Cultures. Sitophilus oryzae colonies were reared in the laboratory in 0.9-liter glass jars filled with $\approx 300$ g of hard red winter wheat 'Jagger' (Sears et al. 1997) equilibrated to $13.5 \%$ moisture content. Jars were fitted with filter paper and wire mesh lids with 420- $\mu \mathrm{m}$ openings to prevent insect escape. The colony, originating from eastern Kansas and collected before 1960, was maintained in the laboratory at $27.0 \pm$ $0.5^{\circ} \mathrm{C}$ and $60 \pm 5.0 \% \mathrm{RH}$ with a photoperiod of $14: 10$ (L:D). Rearing density was $\approx 100$ starting adults per $300 \mathrm{~g}$ of wheat.

Kernels containing S. oryzae of the correct life stage were selected using radiographic analyses. Founding adults were removed after $24 \mathrm{~h}$ and the colonies were returned to the growth chamber for $14 \mathrm{~d}$ (small larvae), $25 \mathrm{~d}$ (large larvae), $\approx 30 \mathrm{~d}$ (pupae), or $\approx 35 \mathrm{~d}$ (preemergent adults). Double-sided adhesive tape was used to hold the wheat kernels from the insect colonies to previously exposed $\mathrm{x}$-ray films for easy handling. The films were then individually $\mathrm{x}$-rayed and processed following the methods described in Toews et al. (2006). Kernels containing preemergent adults were selected based on the presence of adults in kernels that had not yet chewed an exit tunnel to the outside of the kernel. Kernels containing a single insect of the targeted life stage were manually culled using forceps and grouped by life stage in aluminum baking dishes. These kernels were immediately placed in a forced air laboratory oven for $1 \mathrm{~h}$ at $130^{\circ} \mathrm{C}$ to kill the insects. Kernels were then stored in sealed plastic bags in the freezer at $-27^{\circ} \mathrm{C}$. The body and tunnel dimensions (length and width) of 25 representative small larvae, large larvae, and adults were measured from the radiographs by using a stage micrometer.

Insect Infestation Densities. Ten levels of infestation for each life stage were selected based on preliminary data, suggesting a range of insect fragments below and above the defect action level. Uninfested wheat was obtained immediately after harvest directly 
from a grower in Dickinson Co., KS, who used standard agronomic practices. The wheat was cleaned with multiple passes over a mechanical dockage tester (model XT2, Carter Day International, Minneapolis, MN) to ensure all foreign material and potential external infesting insects were removed. Subsamples of the clean wheat were $\mathrm{x}$-rayed as described above, but they showed no signs of insect infestation. In preparation for milling, $100 \pm 0.1$-g samples of clean wheat $(\approx 3,150$ kernels $)$ were weighed on a microbalance and stored in heavy plastic bags. Infested kernels were then added to the clean wheat at the following experimental densities: $0,10,20,40,60,80,100,120,140$, or 160 kernels (small or large larvae); $0,5,10,15,20$, $30,40,50,60$, or 70 kernels (pupae); and $0,1,2,3,4$, $5,6,7,8$, or 9 kernels (adults). For consistency, the equivalent number of sound kernels was removed from each 100-g sample before introducing the infested kernels. Five replicates of each infestation density were milled.

Milling. Wheat samples (100 g) were individually milled on an experimental Brabender Quadrumat Sr. mill (type 12-10-N87, C. W. Brabender Instruments, Inc., Hackensack, NJ) at the Hard Winter Wheat Quality Laboratory located at the USDA-ARS Grain Marketing and Production Research Center, Manhattan, KS. This 4-roll milling system is commonly used to produce production equivalent test flours, and it has a milling efficiency of $\approx 60 \%$; therefore, each $100 \mathrm{~g}$ of whole wheat yielded $60.0 \pm 5.0 \mathrm{~g}$ of flour. Wheat samples, initially at $11.4 \%$ moisture, were tempered to $15 \%$ moisture and then milled starting with the negative controls (0 infested kernels) and continuing through the increasing infestation densities within a particular life stage. Five hundred grams of clean wheat was milled between life stage treatments to remove insect fragments that may have accumulated inside the mill. Flour was stored in 300-ml polyethylene jars with tight fitting lids.

Spectral Data Collection. The Bruker Optic's Matrix I FT-NIR spectrometer, which uses the diffuse reflectance technique, was used to collect spectral data (835-2502 nm) of wheat flour containing varying $S$. oryzae fragments. This instrument was described in detail by Armstrong et al. (2006). Each flour sample was poured in a glass-bottomed cylindrical bowl ( 85 $\mathrm{mm}$ in diameter) equipped with a stirring paddle to continuously mix the sample while rotating the bowl during which time multiple reflectance scans were collected. Two replicates, each consisting of the spectra of 100 scans per flour sample, were averaged into one final spectrum that was assigned to that replicate.

Fragment Counts. A direct count of the insect fragments from each milled sample was obtained to compare against the NIRS-predicted results. The standard flotation method (AOAC 1996) was scaled-up to collect fragments in the $60 \pm 5$-g flour replicates. Briefly, the AOAC procedure prescribes digesting the flour with hydrochloric acid and then separating the hydrophobic insect fragments from the remaining hydrophilic plant material in a mineral oil and water mixture. After settling, the oil was washed with iso- propanol though lined filter paper that retained nondigested solids. After moistening with $\approx 2 \mathrm{ml}$ of distilled water, the resulting filter papers were examined under a dissecting microscope with darkfield lighting at $30 \times$ magnification. Visual identification of S. oryzae fragments followed previously published methods (Kurtz 1956, Gentry et al. 1991) and practice on preliminary data sets previously scored by an experienced technician.

Data Analyses. Standard regression techniques were used to describe the relationship between NIRSpredictions and the resulting number of S. oryzae fragments recovered using the standard flotation method. Regardless of the two NIRS-predicted response variables modeled (NIRS-predicted infested kernels and NIRS-predicted insect fragments), these estimates are based on the total mass of the cumulative fragments detected in the sample. Data were fit using TableCurve 2D software (Systat Software Inc. 2002) and final prediction equation parameters or coefficients were based on the pattern of residuals, lack-of-fit tests, and $r^{2}$ values (Draper and Smith 1981). Confidence intervals (95\% CI) were used to estimate the interval around the observed mean for insect fragments from the same population, whereas prediction intervals (95\% PI) were used to relate the current findings on fragment numbers to a future observation. Specifically, we used the upper boundary of insect fragments from the prediction interval to show how many infested kernels containing S. oryzae of a known age could be milled and still produce flour with acceptable number of fragments based on the FDA standard.

NIR spectra were analyzed with partial least squares (PLS) regression analysis by using GRAMS (Thermo Electron Corp. 2006), a spectral analysis software. Independent variables (number of infested kernels or number of insect fragments) by life stage (small larvae, large larvae, pupae, adults, or mixed life stages) were assigned to corresponding spectral data. Parameters chosen in the PLSPlus/IQ software were PLS-1 calibration type, cross-validation diagnostic type with one file out, mean centering data preparation, and no path length or baseline corrections. This method of cross-validation attempts to emulate predicting "unknown" samples by using the training data itself; in a one-file out cross-validation, a single sample is left out and predicted using the model developed using the remaining data set (Galactic Industries Corporation 1996). The wavelength range of $1,000-2,500 \mathrm{~nm}$ was used in calibration model development to eliminate the noise observed in the $<1,000$-nm region. Parameters used to evaluate calibration models developed for each insect life stage included the coefficients of determination $\left(R^{2}\right)$, standard error of cross validation (SECV), and PLS regression coefficients. The SECV was used as an indicator of the "best" number of independent variables or factors needed for the calibration model. The PLS regression coefficients give an indication of the wavelengths (shown as positive and negative peaks in the plot) that are more heavily weighted at wavelengths that contributed most to the calibration model. 
Table 1. Mean \pm SEM $(n=25)$ S. oryzae body and tunnel dimensions (millimeters) by life stage

\begin{tabular}{|c|c|c|c|c|}
\hline Life stage & Body length & Body width & Tunnel length & Tunnel width \\
\hline Small larvae & $0.98 \pm 0.05 \mathrm{~d}$ & $0.41 \pm 0.01 \mathrm{c}$ & $1.84 \pm 0.09 \mathrm{~b}$ & $0.66 \pm 0.02 b$ \\
\hline Large larvae & $2.54 \pm 0.06 \mathrm{c}$ & $1.42 \pm 0.03 \mathrm{a}$ & $4.13 \pm 0.06 \mathrm{a}$ & $1.61 \pm 0.02 \mathrm{a}$ \\
\hline Pupae & $3.64 \pm 0.07 \mathrm{a}$ & $1.40 \pm 0.02 \mathrm{a}$ & $4.17 \pm 0.06 \mathrm{a}$ & $1.62 \pm 0.03 \mathrm{a}$ \\
\hline Preemergent adults & $3.46 \pm 0.04 \mathrm{~b}$ & $1.04 \pm 0.02 b$ & $4.07 \pm 0.04 a$ & $1.59 \pm 0.02 \mathrm{a}$ \\
\hline
\end{tabular}

Means within columns followed by the same letter are not significantly different $(F$ range $=286.4-475.8 ; \mathrm{df}=3,96 ; P<0.01$; one-way ANOVA). Means separations follow the lsmeans test $(P<0.05)$ (SAS Institute 1999).

Regression models were developed to explain the relationship between predicted number of S. oryzae fragments from the NIRS calibration models and actual number of fragments obtained with the standard flotation method. Inverse prediction confidence intervals on linear regression models (Neter et al. 1996) were calculated to demonstrate how NIRS predicted counts of insect fragments (a quick and nondestructive approximate measure) could be used to estimate the number of actual insect fragments (a precise but destructive and time-consuming measure) with 95\% confidence.

\section{Results}

S. oryzae body dimensions generally changed with life stage, whereas tunnel dimensions changed little. Tunnels in wheat kernels did not increase from large larva through preemergent adult life stages, whereas individual body length and width changed significantly with life stage. Tunnel length and width more than doubled between the small larvae and large larvae life stages (Table 1). Interestingly, pupae were significantly longer and wider than adults.

Older insects and infestation density increased the number of insect fragments observed in the finished flour. Samples produced by milling more infested kernels yielded a proportional increase in insect fragments (Table 2). Small larvae contributed fewer fragments than similar numbers of large larvae. A single small larva contributed $0.4 \pm 0.03$ fragments $(95 \% \mathrm{CI}=$ $0-1.8 ; 95 \%$ PI $=0-15.1$ ), whereas an individual large larva contributed $0.7 \pm 0.04$ fragments $(95 \% \mathrm{CI}=$ $0-8.1 ; 95 \% \mathrm{PI}=0-26.7)$. In comparison, a single pupa contributed $1.5 \pm 0.1$ fragments $(95 \% \mathrm{CI}=0-10.8 ; 95 \%$ $\mathrm{PI}=0-31.4)$ and a single adult contributed $27.0 \pm 1.8$ fragments $(95 \% \mathrm{CI}=11.2-46.3 ; 95 \% \mathrm{PI}=0-109.2)$. A linear relationship explained much of the variability between the number of infested kernels and the number of resulting insect fragments in the flour (Fig. 1A-D). Appendages of the head and thorax, sclerotized internal organs, and general body cuticle were observed in the adult fragments, but immature fragments were primarily comprised of head capsule, mandibles, and tarsal segments. The $95 \%$ prediction intervals suggest that the maximum number of infested wheat kernels that could be milled in a 100-g wheat sample and still produce flour below the FDA defect action level of 75 fragments in $50 \mathrm{~g}$ flour (upper $95 \%$ CL would be below 90 fragments in $60 \mathrm{~g}$ of flour) was 155 kernels containing small larvae $(95 \%$ PI $=54.5-$ $89.5), 90$ containing large larvae $(95 \% \mathrm{PI}=43.7-89.7)$, 39 containing pupae (95\% PI $=36.5-89.7)$, and 0 containing adults $(95 \% \mathrm{PI}=0-80.0)$.

NIRS calibration models developed with these data satisfactorily predicted both the number of infested kernels in that flour sample and number of insect fragments in the flour sample. For estimation of insect fragments, PLS regression coefficients obtained by NIRS showed that important wavelengths used to differentiate insect fragments from the flour matrix occurred at $\approx 1,180,1,360,1,440,1,620,1,725,1,765,1,900$, 1,920, and 1,950 nm (Fig. 2). Similar PLS regression coefficients were used to develop calibration models to estimate the number of infested kernels that were milled to produce that sample. The coefficients of determination $\left(R^{2}\right)$ suggested that the calibration models described comparatively more of the variation

Table 2. Mean \pm SEM $(n=5)$ number of insect fragments recovered in flour milled from $100 \mathrm{~g}$ of wheat containing kernels infested with $S$. oryzae small larvae, large larvae, pupae, or adults

\begin{tabular}{|c|c|c|c|c|c|c|c|}
\hline \multicolumn{2}{|c|}{ Small larvae } & \multicolumn{2}{|c|}{ Large larvae } & \multicolumn{2}{|c|}{ Pupae } & \multicolumn{2}{|c|}{ Preemergent adults } \\
\hline $\begin{array}{l}\text { No. infested } \\
\text { kernels }\end{array}$ & $\begin{array}{c}\text { No. } \\
\text { fragments }\end{array}$ & $\begin{array}{l}\text { No. infested } \\
\text { kernels }\end{array}$ & $\begin{array}{c}\text { No. } \\
\text { fragments }\end{array}$ & $\begin{array}{c}\text { No. infested } \\
\text { kernels }\end{array}$ & $\begin{array}{c}\text { No. } \\
\text { fragments }\end{array}$ & $\begin{array}{c}\text { No. infested } \\
\text { kernels }\end{array}$ & $\begin{array}{c}\text { No. } \\
\text { fragments }\end{array}$ \\
\hline 0 & $0.0 \pm 0.0$ & 0 & $0.0 \pm 0.0$ & 0 & $0.0 \pm 0.0$ & 0 & $0.0 \pm 0.0$ \\
\hline 10 & $2.8 \pm 0.9$ & 10 & $5.8 \pm 1.1$ & 5 & $12.5 \pm 1.1$ & 1 & $37.8 \pm 7.4$ \\
\hline 20 & $5.6 \pm 1.0$ & 20 & $13.8 \pm 2.0$ & 10 & $20.6 \pm 2.1$ & 2 & $50.0 \pm 8.0$ \\
\hline 40 & $15.0 \pm 2.5$ & 40 & $30.8 \pm 2.1$ & 15 & $23.0 \pm 2.5$ & 3 & $84.6 \pm 12.3$ \\
\hline 60 & $27.8 \pm 5.1$ & 60 & $45.6 \pm 4.5$ & 20 & $26.2 \pm 4.2$ & 4 & $116.6 \pm 6.5$ \\
\hline 80 & $35.8 \pm 4.5$ & 80 & $66.8 \pm 3.3$ & 30 & $56.2 \pm 5.0$ & 5 & $136.2 \pm 18.5$ \\
\hline 100 & $41.8 \pm 4.8$ & 100 & $85.0 \pm 5.3$ & 40 & $59.2 \pm 4.5$ & 6 & $190.4 \pm 28.9$ \\
\hline 120 & $54.0 \pm 2.4$ & 120 & $90.4 \pm 8.0$ & 50 & $80.3 \pm 9.5$ & 7 & $229.2 \pm 24.1$ \\
\hline 140 & $57.4 \pm 3.1$ & 140 & $101.6 \pm 6.9$ & 60 & $97.8 \pm 11.9$ & 8 & $227.2 \pm 13.0$ \\
\hline 160 & $83.4 \pm 7.1$ & 160 & $105.4 \pm 6.0$ & 70 & na & 9 & $265.8 \pm 34.1$ \\
\hline
\end{tabular}

na, no data available. 

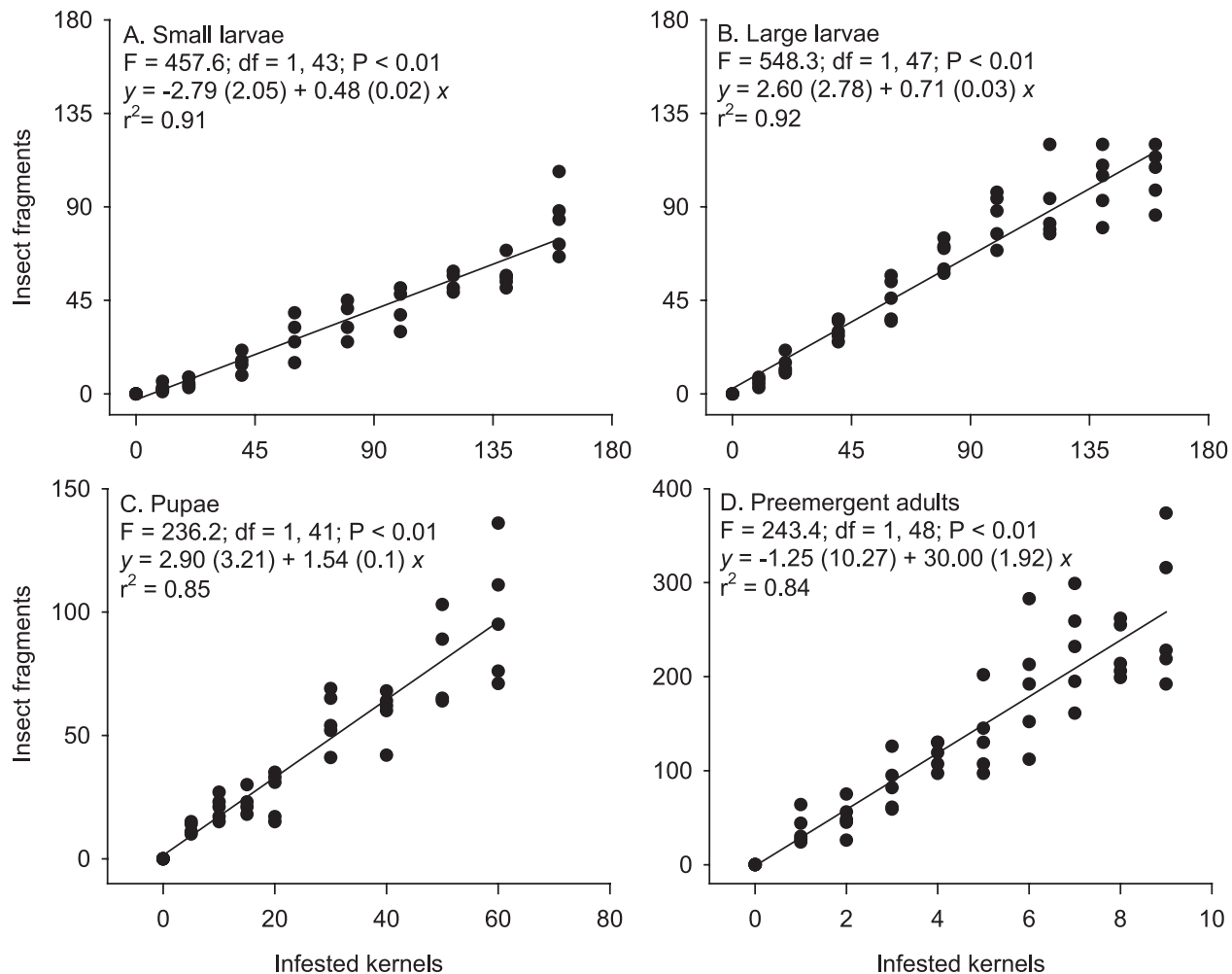

Fig. 1. Relationship between number of infested kernels/100 g of wheat and S. oryzae insect fragments resulting from small larvae (A), large larvae (B), pupae (C), and preemergent adults (D). Numbers in parentheses after equation parameters indicate standard errors of parameter estimates.

for the number of infested kernels containing small and large larvae than for kernels containing pupae or adults (Table 3). Similarly, the calibration models for fragments from small and large larvae explained more variation in the data than the calibration models for fragments from pupae or adults (Table 4). Direct model comparisons between predictions of infested kernels versus fragments are difficult because model fitting implied the need for different numbers of factors for each life stage; differing numbers of factors should be interpreted similar to regression models with multiple independent variables.

Modeling the relationship between NIRS-predicted infested kernels (or fragments) and the known number of infested kernels (or observed fragments) necessitated different types of curves. Lack-of-fit tests and patterns of residuals suggested that only a linear relationship existed between the NIRS-predicted number of infested kernels and the actual density of infested kernels (Fig. 3A-E). Interpretation of lackof-fit tests implied that quadratic models best explained the relationship between the NIRS-predicted number of insect fragments and the observed fragments (data not shown); however, these data were also fit to linear models (Fig. 4A-E), because we wanted to calculate inverse prediction confidence intervals, which are based on a linear curve. The $95 \%$ inverse prediction confidence intervals showed that predictions of 51, 53, 43, 0 , and 21 fragments (for small larvae, large larvae, pupae, adults, or mixed stages, respectively) would fall below the DAL of 75 fragments in $50 \mathrm{~g}$ of flour (upper 95\% CI would be below 90 fragments in $60 \mathrm{~g}$ of flour). Similarly, NIRS-predicted fragment counts of 98, 117, 108, 225, and 152 fragments (from small larvae, large larvae, pupae, adults, or mixed stages, respectively) would be above the FDA defect action level (lower 95\% CI would be above 90 fragments in $60 \mathrm{~g}$ of flour).

There were obvious differences in the time and equipment requirements to determine the number of insect fragments in flour using the two methods. For the NIRS process, the spectrometer required $\approx 1 \mathrm{~min}$ per sample to complete the scans. The technician required an additional minute to log the data on the computer, transfer the flour back to the storage jar, thoroughly clean the sampling cup with compressed air, manually enter a new sample number, and load a new sample into the sample cup. In comparison, the standard flotation method required $\approx 2.5 \mathrm{~h}$ per batch of six samples $(\approx 75$ samples could be processed during this time by using NIRS). Although we processed a batch of six samples simultaneously with the flotation, this required six sets of glassware and other laboratory equipment. Equipment-wise, the NIRS method required only the NIRS scanner and a can of compressed air. By comparison, each sample processed with the 


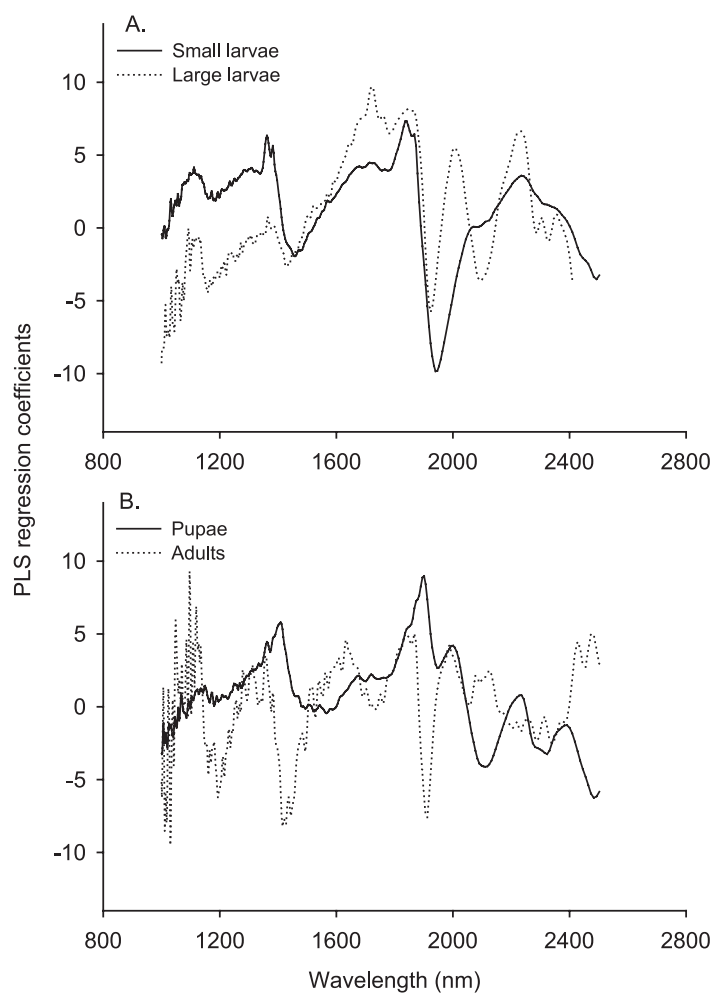

Fig. 2. PLS regression coefficients for NIRS calibration models developed to enumerate $S$. oryzae insect fragments resulting from small and large larvae (A) or pupae and adults (B) in wheat flour.

flotation method required a sieve, reflux apparatus, Wildman trap flask, several beakers, hot-plate with stirring bar, watch glass, and flask in addition to hot tap water, hydrochloric acid solution, isopropanol solutions, mineral oil, detergent, and tetrasodium ethylenediaminetetraacetate.

\section{Discussion}

Various parameters contribute to the number of fragments produced by a single insect. Sachdeva (1978) estimated that milling wheat containing dead S. oryzae produced $>2.6$ times more fragments than live individuals. Perez-Mendoza et al. (2005) reported that a single $R$. dominca larva or pupa produced vir-

Table 3. Performance of NIRS calibration models developed for enumerating $S$. oryzae infested kernels in wheat flour $(60 \mathrm{~g})$ by life stage

\begin{tabular}{lccrc}
\hline \multicolumn{1}{c}{ Model } & $\begin{array}{c}\text { No. } \\
\text { factors }\end{array}$ & SECV & $n^{a}$ & $R^{2}$ \\
\hline Small larvae & 7 & 18.50 & 43 & 0.88 \\
Large larvae & 6 & 15.10 & 48 & 0.92 \\
Pupae & 5 & 9.31 & 39 & 0.83 \\
Preemergent adults & 4 & 1.93 & 48 & 0.56 \\
Mixed stages & 5 & 31.96 & 178 & 0.58 \\
\hline
\end{tabular}

${ }^{a} n$ is number of observations.
Table 4. Performance of NIRS calibration models developed for enumerating $S$. oryzae fragments in wheat flour $(60 \mathrm{~g})$ by life stage

\begin{tabular}{lccrr}
\hline \hline \multicolumn{1}{c}{ Model } & $\begin{array}{c}\text { No. } \\
\text { factors }\end{array}$ & SECV & $n^{a}$ & $R^{2}$ \\
\hline Small larvae & 3 & 15.25 & 43 & 0.71 \\
Large larvae & 5 & 16.89 & 48 & 0.81 \\
Pupae & 3 & 20.99 & 39 & 0.60 \\
Preemergent adults & 6 & 69.36 & 48 & 0.50 \\
Mixed stages & 5 & 54.19 & 178 & 0.42 \\
\hline
\end{tabular}

${ }^{a} n$ is number of observations.

tually identical numbers of fragments, and a similar pattern was shown here with S. oryzae. Rhyzopertha dominica $(\mathrm{F}$.) adults produced only one half the number of fragments (Perez-Mendoza et al., 2005) observed here with S. oryzae adults. The procedure followed by Perez-Mendoza et al. (2005) involved drying the specimens in a laboratory oven, but they did not freeze the insect-infested kernels before milling. It is unknown whether freezing may cause the sclerotized adult cuticle to shatter into more fragments during milling. Wingfield and Pedersen (1985) reported that insect life stage, species, body size, and moisture content affected fragmentation, whereas Harris et al. (1952) showed that mill size, flow, and equipment were also important. We hypothesize that substantially more fragments were obtained with $S$. oryzae compared with $R$. dominica adults, because $S$. oryzae adults are up to $1.5 \mathrm{~mm}$ longer (Rees 2004) and have longer appendages (legs, antennae, and snout) compared with $R$. dominica.

Analyses of spectra generated with NIRS highlight differences in chemical constituents among biological materials (Ridgway and Chambers 1996). The chitin of insect procuticle is comprised of repeating $n$-acetylglucosamine sugars (Chapman 1982); $\mathrm{CH}_{3}$ and $\mathrm{CH}_{2}$ are commonly occurring moieties in insect cuticular lipids (Lockey 1988). The $\mathrm{CH}, \mathrm{CH}_{2}, \mathrm{CH}_{3}$, and $\mathrm{C}=\mathrm{O}$ chemical constituents present in chitin were important parameters that may have allowed for prediction of insect fragments in flour as shown in the PLS regression coefficients plots. Some wavelengths $(\approx 1,620$ and $1,765 \mathrm{~nm}$ ) that were important for identifying $S$. oryzae insect fragments were identical to those used by Perez-Mendoza et al. (2005) to quantify $R$. dominica insect fragments in flour. These regions generally correspond with the first and second $\mathrm{CH}$ absorption overtones of $\mathrm{CH}, \mathrm{CH}_{2}$, and $\mathrm{CH}_{3}$ groups (Murray and Williams 1990, Shenk et al. 1992, Osborne et al. 1993). Likewise, Maghirang et al. (2003) also found NIR wavelengths at $\approx 1,370$ and $1,610 \mathrm{~nm}$ as important for identifying whole S. oryzae inside wheat kernels. Each independently developed calibration model identified similar PLS regression coefficients across studies and types of sampling equipment, thereby suggesting robust utility of these wavelengths.

Several factors complicate the development of a more accurate NIRS calibration model. For example, there is some error associated with direct enumeration 

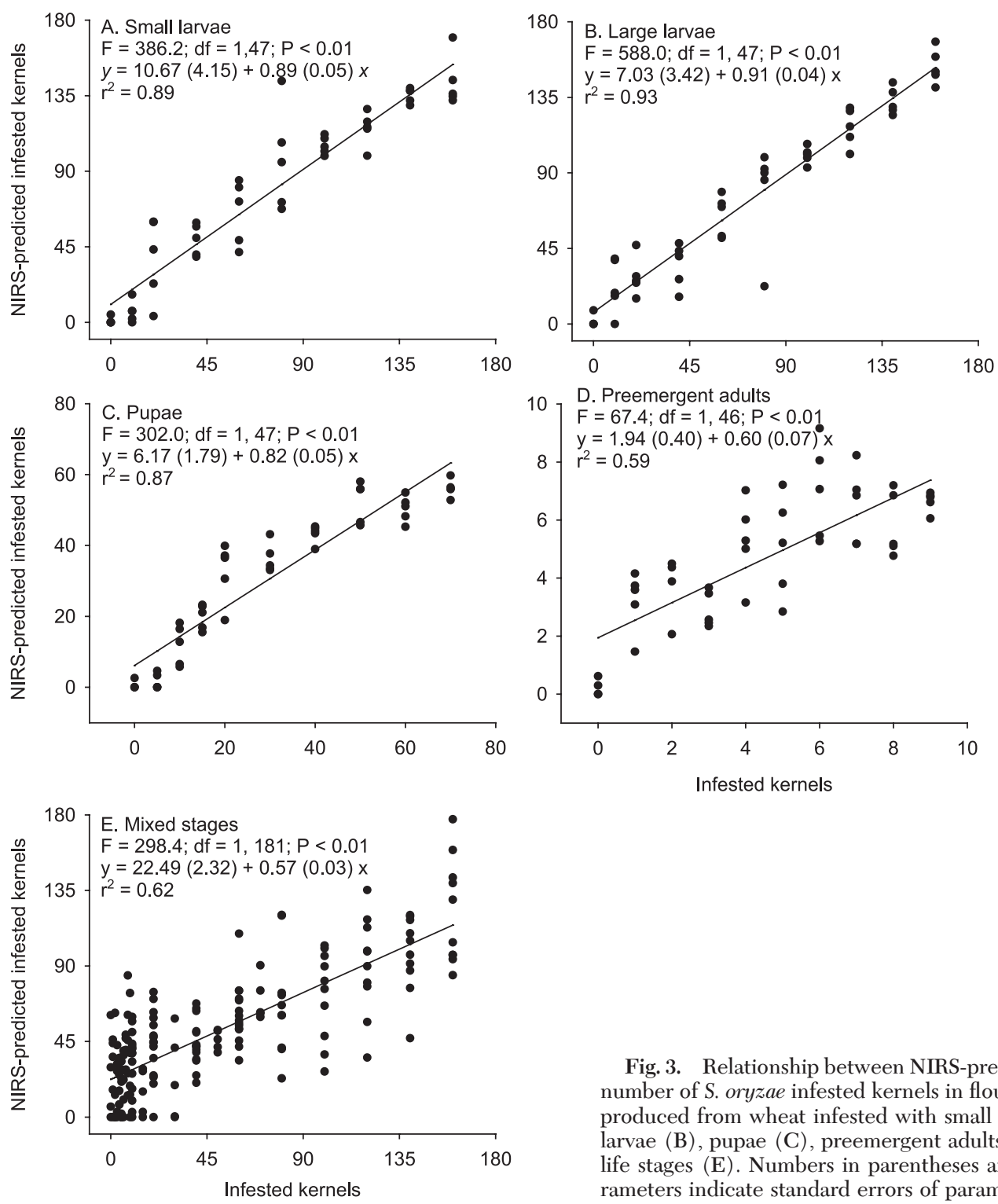

Fig. 3. Relationship between NIRS-predicted and actual number of S. oryzae infested kernels in flour samples $(60 \mathrm{~g})$ produced from wheat infested with small larvae (A), large larvae (B), pupae (C), preemergent adults (D), and mixed life stages $(\mathrm{E})$. Numbers in parentheses after equation parameters indicate standard errors of parameter estimates.

of insect fragments by using the flotation method. Wingfield and Pedersen (1985) milled insect-infested wheat and then sent five representative flour samples to two separate reputable laboratories; on average, one laboratory reported 200 more insect fragments in the samples compared with the other. Similarly, Brader et al. (2002) documented wide variation in fragment counts among three laboratories that received subsamples of flour produced by milling wheat spiked with known numbers of infested kernels. After extensive study and practice on preliminary samples, a single person counted the fragments in our study to reduce variability due to processing the samples. Therefore, any processing error should be reduced and be consistent across the samples. The fitting of a linear curve without significant lack of fit to the plots of infested kernels versus number of fragments at least suggests good precision in counting the fragments. A second factor complicating calibration is different sized fragments. Although NIRS-predicted counts are based on the total mass of the cumulative fragments, numbers of fragments quantified with the standard flotation method are irrespective of the total mass. Thus, it is difficult to calibrate the novel detection technique to the approved standard when they are not measuring exactly the same parameter. This argument is supported by the fact that linear models were a better fit for predicting the number of infested kernels (a relatively constant mass), but quadratic models were a better fit for predicting the number of fragments (a variable number of fragments could comprise the same mass). 

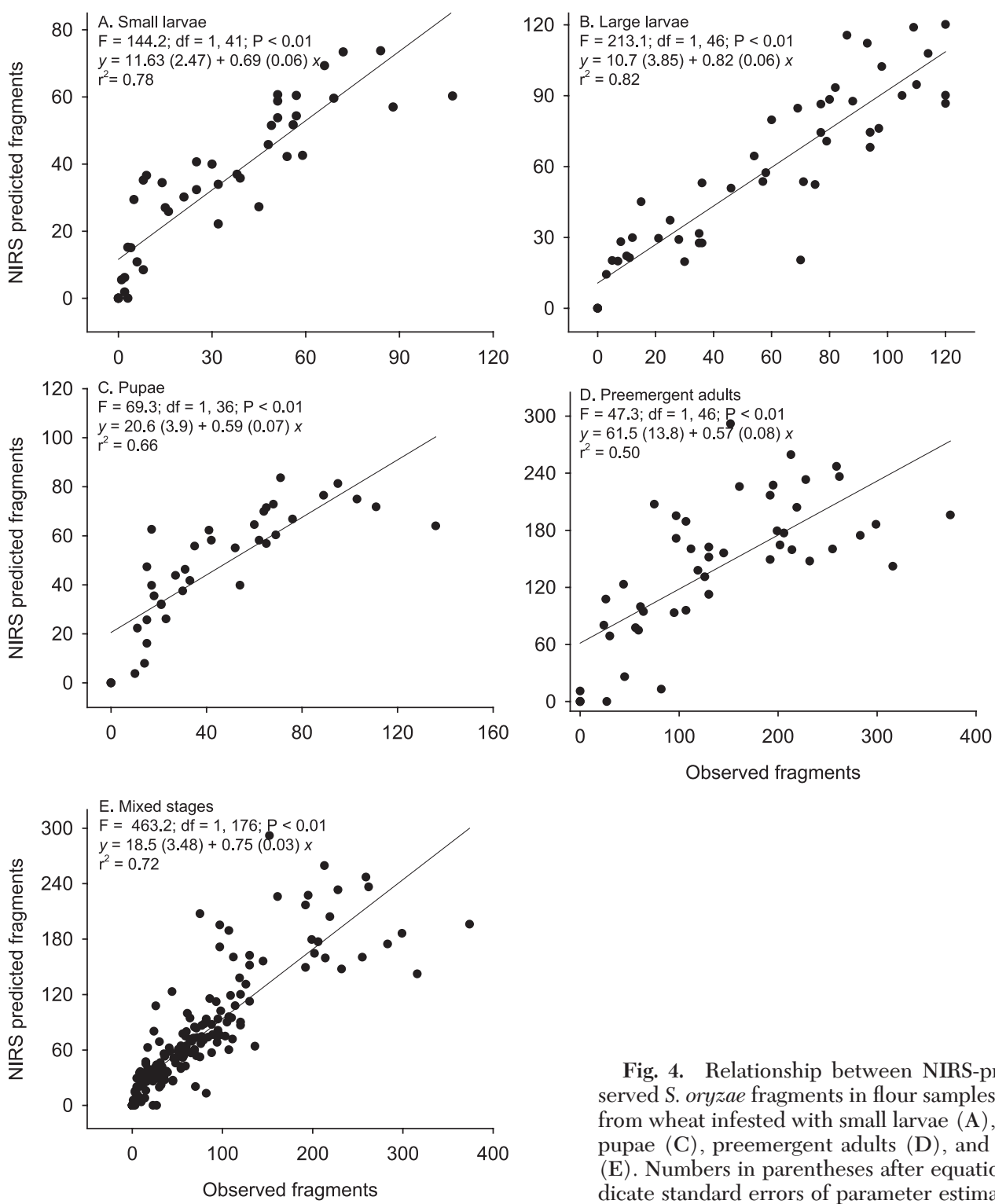

Fig. 4. Relationship between NIRS-predicted and observed S. oryzae fragments in flour samples $(60 \mathrm{~g})$ produced from wheat infested with small larvae (A), large larvae (B), pupae $(\mathrm{C})$, preemergent adults $(\mathrm{D})$, and mixed life stages (E). Numbers in parentheses after equation parameters indicate standard errors of parameter estimates.

Adoption of NIRS for insect fragment analyses has several advantages over the standard flotation method and ELISA procedure. NIR spectrometers are widely available, relatively inexpensive, and presently used in grain processing facilities to measure quality attributes of wheat flour, such as ash, moisture, and protein content, and quality of animal feeds such as crude protein, fat, and starch. NIRS is much faster $(\approx 2 \mathrm{~min}$ to process a sample) compared with the standard flotation method that requires $\approx 2.5 \mathrm{~h}$ to process a sample and the ELISA procedure that requires just over an hour to process a sample (Brader 1997). Even when adjusting for the ability to process more than one sample at a time with the non-NIRS methods, NIRS was more efficient. Furthermore, NIRS estimation of insect fragments requires no special sample

preparation and produces no disposal hazards. The standard flotation method requires a continuous supply of laboratory chemicals (i.e., hydrochloric acid, mineral oil, and isopropanol), whereas the ELISA procedure also requires purchase of disposable kits and reagents for each sample. The ELISA method to detect myosin also has several technical issues that impact its accuracy: there are variable amounts of myosin in different life stages (Schatzki et al. 1993) and myosin degrades during the first $2 \mathrm{wk}$ after insect death, but it remains relatively stable after that initial decay period (Atui et al. 2007). After the calibration model is developed, NIRS determination does not require highly skilled labor for operation. By comparison, the standard flotation method requires detailed training in microanalytical entomology to recognize the insect 
fragments (Kurtz and McCormack 1965), and the myosin ELISA procedure requires training in immunological detection technique. Finally, the standard flotation and ELISA procedures are both destructive sampling methods, whereas NIRS is nondestructive.

Disadvantages to using NIRS for detection and estimation of insect fragments in wheat flour generally relate to the imprecise nature of the estimates, complex development of robust calibration models, ongoing spectrometer calibration, and consistency across several individual instruments. Inverse prediction intervals developed here and in Perez-Mendoza et al. (2005) suggest that NIRS-predicted immature fragment counts below $\approx 50$ fragments for $R$. dominica and S. oryzae would not exceed the FDA threshold of 75 fragments in a 50-g sample. Likewise, NIRS-predicted fragment counts above 105 fragments would likely have $>75$ actual fragments in a 50 -g sample. These data suggest that one would not be able to determine whether the number of fragments in a sample was above or below the threshold if NIRS-predicted fragment counts were between $\approx 50$ and 105 fragments; similarly, NIRS-predicted fragments resulting from milling wheat infested with adult $S$. oryzae were highly variable. Because NIRS data are quick and inexpensive, this situation could be improved by analyzing a few more samples from that lot of flour to try to determine the actual fragment level. There are currently no data on processing flour samples with more than one insect species present, but this may not be a serious issue because NIRS can differentiate among whole adults (Dowell et al. 1999). Development of a calibration model is critical for NIRS to be useful for estimating insect fragments in flour samples. Several commercial laboratories have the expertise to develop these models. To address the need for continuous NIRS calibration, at least one manufacturer of NIR spectrometers offers an internet-enabled analytical system where an expert remotely monitors and continuously calibrates the system (Dominy and Buckley 2003). A second benefit of this service is that the expert could interpret each sample on a per fee basis.

Although incoming wheat will likely contain mixed life stages, we hypothesize that methods of quantifying insect fragments should be focused on fragments produced by small- and medium-sized larvae. Incoming wheat in most commercial facilities is cleaned with entoleters (impact machines), scalpers, and aspiration before milling (Mills and Pedersen 1992). Wheat thrown by centrifugal force inside an entoleter during the cleaning process would likely break hollow kernels, such as those chewed by large larvae. Data presented here show that the cavity size inside a wheat kernel remained static from the late larval through preemergent adult life stages, suggesting that estimation of fragments from these life stages may not be important. Broken kernels and newly exposed insects resulting from entoleters would be easily separated from the sound kernels; therefore, no insect fragments from these sources would be evident in the final millstream. Unfortunately, not all mills use this type of cleaning equipment and there are no hard data on entoleter use during the grain cleaning process at domestic mills. Rigorous scientific study on the performance of entoleters is needed to test this hypothesis.

\section{Acknowledgments}

We thank Laura McLaughlin at the Grain Quality and Structure Research Unit (Grain Marketing and Production Research Center) for milling the wheat samples, and Ann Redmond for conducting the acid hydrolysis procedure on each flour sample. Jaclyn Rowan, Orrin Holle, Caleb Doll, Matt Kennedy, Luis Sainz, and Susan Romero provided excellent technical support. The FT-NIRS spectrometer was provided by the QTA group of the Cognis Corp. (Cincinnati, $\mathrm{OH})$. We greatly appreciate Terry Arbogast and Thomas Pearson who provided helpful comments to an earlier manuscript draft. This work was funded with partial support from USDA-CSREES (RAMP) under agreement 00-511-01-9674.

\section{References Cited}

[AACC] American Association of Cereal Chemists. 1995. Approved methods of the American Association of Cereal Chemists, 9th ed. American Association of Cereal Chemists, St. Paul, MN.

[AOAC] Association of Official Analytical Chemists. 1996. 16.5.11 AOAC Official method 972.32, Light filth (pre- and post-milling) in flour (white), p. 18. In Official methods of analysis of Association of Official Analytical Chemists International, 16th ed. Association of Official Analytical Chemists International, Gaithersburg, MD.

Armstrong, P. R., E. B. Maghirang, F. Xie, and F. E. Dowell. 2006. Comparison of dispersive and Fourier-transform NIR instruments for measuring grain and flour attributes. Appl. Eng. Agric. 22: 453-457.

Atui, M. B., P. W. Flinn, S.M.N. Lazzari, and F. A. Lazzari. 2007. Detection of Rhyzopertha dominica larvae in stored wheat using ELISA: the impact of myosin degradation following fumigation. J. Stored Prod. Res. 43: 156-159.

Bernton, H. S., and H. Brown. 1967. Insects as potential sources of ingestant allergens. Ann. Allergy 25: 381-387.

Birch, L. C. 1945. The influence of temperature, humidity, and density on the oviposition of the small strain of Calandra oryzae L. and Rhizopertha dominica Fab. (Coleoptera). Aust. J. Exp. Biol. Med. Sci. 23: 197-203.

Brader, B. 1997. Are food sanitation assays meaningful? Cereal Foods World 42: 759-760.

Brader, B., R. C. Lee, R. Plarre, W. Burkholder, G. B. Kitto, C. Kao, L. Polston, E. Dorneanu, I. Szabo, B. Mead, B. Rouse, D. Sullins, and R. Denning. 2002. A comparison of screening methods for insect contamination in wheat. J. Stored Prod. Res. 38: 75-86.

Chapman, R. F. 1982. The insects: structure and function, 3rd ed. Harvard University Press, Cambridge, MA.

Dominy, S. F., and E. Buckley. 2003. Alternative analysis. World Grain, June: 66-69.

Dowell, F. E., J. E. Throne, and J. E. Baker. 1998. Automated nondestructive detection of internal insect infestation of wheat kernels by using near-infrared spectroscopy. J. Econ. Entomol. 91: 899-904.

Dowell, F. E., J. E. Throne, D. Wang, and J. E. Baker. 1999. Identifying stored grain insects using near-infrared spectroscopy. J. Econ. Entomol. 92: 165-169.

Draper, N. R., and H. Smith. 1981. Applied regression analysis, 2nd ed. Wiley, New York.

[FDA] Food and Drug Administration. 1997. 578.450 Wheat flour-adulteration with insect fragments and 
rodent hairs (CPG 7104.06). Compliance Policy Guides Manual, Chapter 5, Foods, color and cosmetics, Sub chapter 578-processed grain. (http:/ / www.fda.gov/ora/ compliance_ref/cpg/default.htm\#1998).

Galactic Industries Corporation. 1996. PLSplus/IQ for Grams/32 and Grams/386. Galactic Industries Corporation, Salem, NH.

Gentry, J. W., K. L. Harris, and J. W. Gentry, Jr. 1991. Microanalytical entomology for food sanitation control. Association of Official Analytical Chemists, Melbourne, FL.

Haff, R. P., and D. C. Slaughter. 2004. Real-time x-ray inspection of wheat for infestation by the granary weevil, Sitophilus granarius (L.). Trans. ASAE 47: 531-537.

Harris, K. L., J. F. Nicholson, L. K. Randolph, and J. L. Trawick. 1952. An investigation of insect and rodent contamination of wheat and wheat flour. J. Am. Off. Anal. Chem. 35: 115-157.

Karunakaran, C., D. S. Jayas, and N.D.G. White. 2003. Soft $\mathrm{x}$-ray inspection of wheat kernels infested by Sitophilus oryzae. Trans. ASAE 46: 739-745.

Kitto, G. B. 1991. A new rapid biochemical technique for quantitating insect contamination in grain. Bull. Assoc. Oper. Millers, March: 5835-5838.

Kurtz, O. L. 1956. Identification of stored products insects by the micromorphology of the exoskeleton. III. Identification of the larval fragments and their significance in sanitation analyses. J. Assoc. Off. Anal. Chem. 39: 990 1014

Kurtz, O. L., and T. H. McCormack. 1965. Comparison of AACC and AOAC methods for extraneous materials in flour. J. Assoc. Off. Anal. Chem. 48: 554-558.

Lockey, K. H. 1988. Lipids of the insect cuticle: origin, composition and function. Comp. Biochem. Physiol. B 89: 595-645.

Maghirang, E. B., F. E. Dowell, J. E. Baker, and J. E. Throne. 2003. Automated detection of single wheat kernels containing live or dead insects using near-infrared reflectance spectroscopy. Trans. ASAE 46: 1277-1282.

Mills, R., and J. Pedersen. 1992. A flour mill sanitation manual. Eagan Press, St. Paul, MN.

Murray, I., and P. C. Williams. 1990. Chemical principles of near-infrared technology, pp. 17-34. In P. C. Williams and K. H. Norris [eds.], Near-infrared technology in the agricultural and foods industries. American Association of Cereal Chemists, St. Paul, MN.

Neter, J., M. H. Kutner, C. J. Nachtsheim, and W. Wasserman. 1996. Applied linear regression models, 3rd ed. Irwin, Chicago, IL.

Osborne, B. G., T. Fearn, and P. H. Hindle. 1993. Practical NIR spectroscopy with applications in food and beverage analysis. Longman Scientific \& Technical, Harlow, United Kingdom.

Perez-Mendoza, J., J. E. Throne, F. E. Dowell, and J. E. Baker. 2003. Detection of insect fragments in wheat flour by near-infrared spectroscopy. J. Stored. Prod. Res. 39: 305312.

Perez-Mendoza, J., P. W. Flinn, J. F. Campbell, D. W. Hagstrum, and J. E. Throne. 2004. Detection of stored- grain insect infestation in wheat transported in railroad hopper-cars. J. Econ. Entomol. 97: 1474-1483.

Perez-Mendoza, J., J. E. Throne, E. B. Maghirang, F. E. Dowell, and J. E. Baker. 2005. Insect fragments in flour: relationship to lesser grain borer (Coleoptera: Bostrichidae) infestation level in wheat and rapid detection using near-infrared spectroscopy. J. Econ. Entomol. 98: 2282 2291.

Quinn, F. A., W. Burkholder, and G. B. Kitto. 1992. Immunological technique for measuring insect contamination of grain. J. Econ. Entomol. 85: 1463-1470.

Rees, D. 2004. Insects of Stored Products. CSIRO Publishing, Collingwood, VIC, Australia.

Ridgway, C., and J. Chambers. 1996. Detection of external and internal insect infestation in wheat by near-infrared reflectance spectroscopy. J. Sci. Food Agric. 71: 251-264.

Russell, G. E. 1988. Evaluation of four analytical methods to detect weevils in wheat: granary weevil, Sitophilus granarius (L.), in soft white wheat. J. Food Prot. 51: 547-553.

Sachdeva, A. S. 1978. Effect of infestation stage, form and treatment on fragment count in flour. M.S. thesis, Kansas State University, Manhattan, KS.

SAS Institute. 1999. SAS/STAT user's guide, version 8. SAS Institute, Cary, NC.

Schatzki, T. F., E. K. Wilson, G. B. Kitto, P. Behrens, and I. Heller. 1993. Determination of hidden Sitophilus granarius (Coleoptera: Curculionidae) in wheat by myosin ELISA. J. Econ. Entomol. 86: 1584-1589.

Sears, R. G., J. M. Moffatt, T. J. Martin, T. S. Cox, R. K. Bequette, S. P. Curran, O. K. Chung, W. F. Herr, J. H. Long, and M. D. Witt. 1997. Registration of 'Jagger' wheat. Crop Sci. 37: 1010.

Sharifi, S., and R. B. Mills. 1971. Developmental activities and behavior of the rice weevil inside wheat kernels. J. Econ. Entomol. 64: 1114-1118.

Shenk, J. S., J. J. Workman, Jr., and M. O. Westerhaus. 1992. Application of NIR spectroscopy to agricultural products, pp. 383-431. In D. A. Burns and E. W. Ciurczak [eds.], Handbook of near-infrared analysis. Marcel Decker, Inc., New York.

Storey, C. L., D. B. Sauer, O. Ecker, and D. W. Fulk. 1982. Insect infestation in wheat and corn exported from the United States. J. Econ. Entomol. 75: 827-832.

Systat Software Inc. 2002. TableCurve 2D version 5.01. Systat Software Inc., Point Richmond, CA.

Thermo Electron Corp. 2006. Grams32/AI version 8.0, PLSPlus/IQ chemometric application. Thermo Electron Corp., Salem, NH.

Toews, M. D., T. C. Pearson, and J. F. Campbell. 2006. Imaging and automated detection of Sitophilus oryzae (Coleoptera: Curculionide) in pupae in hard red winter wheat. J. Econ. Entomol. 99: 583-592.

Wingfield, J., and J. Pedersen. 1985. Insect fragment levels in flour milled from selected commercial wheat blends. Bull. Assoc. Oper. Millers April 1985.

Received 28 February 2007; accepted 17 July 2007. 